Relations industrielles

Industrial Relations

\title{
Flexibilité de l'âge de la retraite, étude publiée par l'organisation de coopération et de développement économique, Paris, 1970, 198 pp.
}

\section{André Roy}

Volume 26, numéro 3, 1971

URI : https://id.erudit.org/iderudit/028256ar

DOI : https://doi.org/10.7202/028256ar

Aller au sommaire du numéro

\section{Éditeur(s)}

Département des relations industrielles de l'Université Laval

\section{ISSN}

0034-379X (imprimé)

1703-8138 (numérique)

Découvrir la revue

Citer ce compte rendu

Roy, A. (1971). Compte rendu de [Flexibilité de l'âge de la retraite, étude publiée par l'organisation de coopération et de développement économique, Paris, 1970, 198 pp.] Relations industrielles / Industrial Relations, 26(3), 775-775. https://doi.org/10.7202/028256ar

Tous droits réservés (C) Département des relations industrielles de l'Université Laval, 1971
Ce document est protégé par la loi sur le droit d'auteur. L’utilisation des services d’Érudit (y compris la reproduction) est assujettie à sa politique d'utilisation que vous pouvez consulter en ligne.

https://apropos.erudit.org/fr/usagers/politique-dutilisation/ 


\section{RECENSIONS}

Flexibilité de l'âge de la retraite, étude publiée par l'Organisation de coopération et de développement économique, Paris, 1970, 198 pp.

L'allongement de la vie humaine fait qu'on s'intéresse de plus en plus à la prolongation de la vie active du travailleur. Cet intérêt repose sur plusieurs raisons, les unes provenant des travailleurs eux-mêmes; les autres de groupes qui détiennent les leviers de commande de la vie sociale et économique.

Pour les personnes âgées, la retraite est un moment dramatique de la vie. Aussi faut-il donner à chacun le maximum de choix entre la poursuite du travail et le départ ou, à tout le moins, s'assurer que la retraite ne se traduise pas par une baisse considérable du niveau de vie de ces personnes.

Pour les dirigeants, qu'il s'agisse de ceux de l'entreprise privée ou de l'entreprise de service public, il y aura, selon les circonstances, soit pression pour mettre le travailleur à la retraite si l'économie se trouve dans une situation de sous-emploi, ce qui est le cas le plus fréquent, ou encore si l'on estime, c'est là aussi un état d'esprit quasi général, que le travailleur d'un certain âge ne peut s'adapter aux changements technologiques, soit encouragement aux personnes âgées de demeurer au travail le plus longtemps possible s'il y a pénurie de main-d'oeuvre ou si l'on se rend compte que, par suite de l'accroissement de la longévité, le coût social pèse de plus en plus lourd sur l'économie nationale.

L'étude ci-dessus présente d'abord une analyse de l'aménagement des régimes de retraite publics dans un certain nombre de pays industrialisés. Cette analyse permet de voir que ces régimes diffèrent beaucoup de l'un à l'autre. $\mathrm{Ce}$ qui en ressort, toutefois, c'est que la rémunération de la retraite est loin dans la plupart des cas de permettre à ces catégories de personnes de maintenir leur niveau de vie à celui que leur permettait leur travail.

Dans un certain nombre de pays, ces régimes sont complétés, il est vrai, par l'existence de régimes privés, le plus souvent à base contributive. Si le nombre de ces plans de pension ont tendance à augmenter, il faut convenir, d'une part, qu'il n'y a guère plus que le tiers des travailleurs qui $y$ sont assujettis et, d'autre part, que ceux-ci étant, dans beaucoup d'autres cas, d'instauration relativement récente, qu'il s'ensuit pour nombre de retraités des prochaines décennies, que la durée de participation n'aura pas été suffisamment longue pour leur permettre d'être assurés d'une retraite équivalente à leurs gains.

A partir de ces éléments de base, l'ouvrage précité présente une étude élaborée de la situation existante dans trois pays: Grande-Bretagne, France et Allemagne fédérale. Les auteurs y considèrent le fait de la flexibilité principalement en fonction de la situation du marché de la main-d'oeuvre vis-à-vis les travailleurs âgés.

Il ressort de l'ensemble de ces études qu'il $y$ a une tendance marquée à la rigidité plutôt qu'à la flexibilité de l'âge de la retraite. Les travailleurs âgés se heurtent donc à de grandes difficultés pour conserver leur emploi.

Mais les auteurs sont unanimes à reconnaître qu'il s'agit là d'une attitude sociale fausse et déplorable. "La flexibilité, écrit Anne-Marie Hackett, constitue un indispensable «préalable » aux applications pratiques de ce droit fondamental de l'homme qui est le droit au travail en dehors de toute considération extrinsèque, dont celle de l'âge ». Quant à Axel New et Gert Elstermann, ils concluent d'une façon encore plus catégorique que «l'âge de la retraite doit être assoupli dans les deux sens », qu'il «faudrait renoncer au principe d'un âge 《normal » de la retraite», qu'il «faudrait persuader les employeurs et les syndicats de cesser d'avoir une attitude négative » et, enfin, qu'il «faudrait assouplir en faveur des personnes âgées, les règlements relatifs aux heures de travail ».

C'est sans doute en s'inspirant de telles conclusions que la société court quelque chance de devenir plus humaine.

André ROY 